\title{
Prevalent Misconceptions and Determinants of Knowledge in Patients with Diabetes Mellitus in a Medical College
}

\author{
Shah SVA ${ }^{1}$, Roy $\mathrm{P}^{2}$, Ansari $\mathrm{F}^{1}$ \\ ${ }^{1}$ Department of Internal Medicine, ${ }^{2}$ Department of Endocrinology \\ Nobel Medical College Teaching Hospital, Biratnagar, Nepal.
}

\begin{abstract}
Background: Diabetes prevalence is high in South Asian countries. In Nepal, numbers are increasing every year. Many patients are aware that they have diabetes only when they develop one of its complications. This study was done to assess the knowledge and awareness of diabetes mellitus and the prevailing myths in outpatients of a tertiary care hospital. Method: It is a cross-sectional study conducted on diabetic patients attending the Department of Endocrine and Internal medicine, Nobel Medical College, over two months using questionnaires. Results: Among 200 diabetics, $67 \%$ believed that insulin is the medication of the last stage, $76 \%$ said insulin once started cannot be stopped.37\% said medicine once started cannot be stopped. There was a misconception regarding the use of COVID-19 vaccines. $27 \%$ of the respondent opinioned that COVID-19 vaccines cause harm to diabetic patients. Conclusion: The survey showed many myths and misconceptions are prevailing in society regarding diabetes which needs to be addressed for better patient outcomes. The age of the participants, duration of illness, and their education status did not correlate with the total score for prevailing myths in the Nepalese population.
\end{abstract}

Keywords: Diabetes Mellitus, Diabetes Complications, Diet, Insulin, Knowledge, Prevention and Control

\section{Introduction}

Diabetes is a key challenging public health dilemma in the 21 st century. It is the time to be aware and make aware to all people of the world. It is to be done for future human health development, early detection, and prevention of the bodily disorder concerned disease. This article has set the aim to assess the awareness and knowledge of diabetics in a tertiary care center in Nepal during the period of two months (2021 August to 2021 October). In Nepal, numbers are increasing every year. Many patients are aware that they have diabetes only when they develop one of its complications. This study was undertaken to assess the knowledge level

Correspondence Author

Dr. Syed Vaqar Ahmad Shah

Assistant Professor

Email: svaqarahmad@hotmail.com in patients with diabetes. DM (Diabetes Mellitus) is one of the most prevalent metabolic diseases which can lead to enormous medical as well as socio-economic consequences ${ }^{1}$. It is currently the fastest-growing debilitating disease in the world. It is estimated that one out of five people aged 20 to 79 live with this disease, while a similar percentage of the population is at risk of developing $\mathrm{it}^{2}$. A major problem with diabetes is that if it is poorly controlled it leads to an increase in microvascular and macrovascular complications such as coronary artery disease, stroke, blindness, kidney failure, foot amputation, the poor blood supply to the limbs leading to increased morbidity. Patient education becomes a central component in the prevention and control of the disease.

Prevention is important because the burden of diabetes and its complications on health care and its 
economic implications are enormous, especially for a South Asian country. As DM is a chronic illness, optimal management requires motivated patients with proper awareness about the disease. DM is associated with significant rates of morbidity and mortality resulting from micro and macrovascular complications. It is one of the most prevailing disorders worldwide, the prevalence for which was estimated globally in 2013, 382 million people live with diabetes and this is expected to rise to 592 million by $2035^{3}$. The self-care practices of individuals are influenced by their knowledge about diabetes, the more they know about their illness, the more they would have self-management skills. Studies have consistently shown that improved glycemic control and strict metabolic control can delay or prevent the progression of complications associated with diabetes. Thus, it is indispensable to ensure that patients' knowledge, attitudes, and practices are adequate.

\section{Methods:}

This study has been approached by a prospective and observational study selecting randomly with 200 diabetics (out-patients). But the inpatients, pediatric patients, pregnant/lactating females have been excluded from the study. Participants were informed that participation was completely voluntary, written consent was obtained from each participant before research, no name was recorded on the questionnaires and all of the personal information of participants was kept confidential. This study was conducted after obtaining the ethical approval from the Institutional Review Committee of Nobel Medical College Teaching Hospital (Ref. No. IRC-NMCTH 556/2021). The participants were explained about the research, the involved benefit and harm in the languages they understood. Voluntary informed consent was taken from the participant for the study.

The required sample size was 120 . Accounting for $20 \%$ partial or non-responders, the minimum sample size needed was 144 . The total number of participants in our study was 200 .
A total of 200 outpatients with diabetes mellitus were interviewed. The data collection form contains information about socio-demographic characteristics, questionnaires about patient awareness on illness, risk factors, symptoms, complications, myths, self-care practices, lifestyle modifications, and management. The myths selected were based on those encountered by the investigators during their clinical practices. Other experts in the field of endocrinology and internal medicine were also consulted in drafting the questionnaire for the knowledge and myth section. To prevent guessing by the participants, the option of don't know was also provided in the questionnaire. A correct score was rewarded 2 points, a wrong answer did not receive any point. The questionnaires were interpreted into local languages, to those who could not understand or read English and the relevant medical terms were explained, wherever required. The questionnaires comprised of:

- Eating sweets and sugary foods cause diabetes.

- People with diabetes always have symptoms attributed to it.

- Having a parent/sibling increases the risk of having diabetes.

- Insulin once started cannot be stopped.

- Insulin is the medicine of the last stage.

- Walking barefoot in the dew-covered lawn early in the morning improves glucose control.

- Alternative medicines (Ayurvedic/yoga) are better than modern medicine in controlling diabetes.

- Ayurvedic medicines do not have any side effects.

- Patients on medication need not be mindful of diet restriction/exercise.

- Eating bitter reduces sugar.

- Stored old rice/half-boiled rice does not increase blood sugar and can be consumed in sufficient quantity.

- Diabetics should not eat root vegetables.

- Removing maad (broth) from rice while cooking helps reduce blood sugar.

- COVID-19 vaccine causes harm to the diabetic patient.

- Protein doesn't raise blood sugar, can be taken in large quantities. 
The entered data were analyzed using IBM SPSS version 20. The Pearson's chi-square test and t-test were used to compare the data. The correlations between total score and baseline participants' characteristics were examined using Spearman's rank correlation. A p-value $<0.05$ was considered significant with a $95 \%$ confidence interval.

\section{Results}

The mean age of the participants was 49.7 years. 44\% (88) of the participants were male. Most of the participants had BMI more than the recommended level for the Asian population- $42 \%$ of the participants were obese and $22 \%$ of the participants were overweight. Oral hypoglycemic agents (OHA) were most commonly prescribed, followed by both insulin and OHA. Only $12 \%$ of the respondents had used Ayurvedic medicine for diabetes. Hypertension and dyslipidemia were the most common concomitant illness in patients with diabetes. The other baseline characteristics are presented in Table 1
Table 1: Baseline characteristics of the participants

\begin{tabular}{|l|l|}
\hline \multicolumn{1}{|c|}{ Variable } & $\begin{array}{c}\text { Frequency } \\
\text { N (\%) }\end{array}$ \\
\hline Age & \\
\hline Mean & 49.7 years \\
\hline Standard Deviation & 11.4 years \\
\hline Gender & \\
\hline Male & $88(44 \%)$ \\
\hline Female & $112(56 \%)$ \\
\hline Body Mass Index & \\
\hline Mean & 24.7 \\
\hline Range & $14-43.5 \mathrm{mg} / \mathrm{km} 2$ \\
\hline Duration of Illness & \\
\hline Mean & 7.6 years \\
\hline Range & $0-26$ years \\
\hline Pharmacotherapy & \\
\hline Oral hypoglycemic agents & $144(72 \%)$ \\
\hline Insulin only & $16(8 \%)$ \\
\hline Both & $40(20 \%)$ \\
\hline $\begin{array}{l}\text { History of Use of Ayurvedic } \\
\text { Medicine }\end{array}$ & $24(12 \%)$ \\
\hline Additional Risk Factors & \\
\hline Smoking & $20(10 \%)$ \\
\hline Alcohol intake & $34(17 \%)$ \\
\hline Concomitant illness & $62(31 \%)$ \\
\hline Hypertension & $48(24 \%)$ \\
\hline Dyslipidemia & $14(7 \%)$ \\
\hline Coronary Artery Disease & $32(16 \%)$ \\
\hline Hypothyroidism & \\
\hline
\end{tabular}

A perfect score in the diabetes myths test section was 30 . The mean score of the respondents was 11.8 with a standard deviation of 3.0. The response of the participants is shown below in table 2. In our study, $67 \%$ responded that insulin is the medication of the last stage, $76 \%$ said insulin once started cannot be stopped. 37\% said medicine once started cannot be stopped. There was a misconception regarding the use of COVID-19 vaccines. $27 \%$ of the respondents considered that the COVID-19 vaccine causes harm to diabetic patients. 
Our findings show that awareness and knowledge about diabetes were less among diabetic patients. $65 \%$ of the respondents said diabetics should not eat root vegetables. $74 \%$ of the respondents believed eating bitter reduces sugar. $67 \%$ of the respondents replied that ayurvedic medications do not have any side effects. (Table 2)

\section{Table 2: Questionnaire about myths and misconceptions of diabetes mellitus}

\begin{tabular}{|l|l|c|c|c|}
\hline SN & \multicolumn{1}{|c|}{ Questions } & Yes \% & No \% & Not sure \% \\
\hline 1 & Eating sweets and sugary foods cause diabetes. & 60 & 30 & 10 \\
\hline 2 & People with diabetes always have symptoms attributed to it. & 55 & 20 & 25 \\
\hline 3 & Having a parent/sibling increases the risk of having diabetes. & 71 & 12 & 17 \\
\hline 4 & Insulin once started cannot be stopped. & 76 & 9 & 15 \\
\hline 5 & Insulin is the medicine of the last stage. & 67 & 12 & 21 \\
\hline 6 & $\begin{array}{l}\text { Walking barefoot in the dew-covered lawn early in the morning } \\
\text { improves glucose control. }\end{array}$ & 55 & 23 & 22 \\
\hline 7 & $\begin{array}{l}\text { Alternative medicines (Ayurvedic/yoga) are better than modern } \\
\text { medicine in controlling diabetes. }\end{array}$ & 47 & 36 & 17 \\
\hline 8 & Ayurvedic medicines do not have any side effects. & 67 & 21 & 12 \\
\hline 9 & Patients on medication need not be mindful of diet restriction/exercise. & 24 & 47 & 29 \\
\hline 10 & Eating bitter reduces sugar. & 74 & 17 & 9 \\
\hline 11 & $\begin{array}{l}\text { Stored old rice/half-boiled rice does not increase blood sugar and can } \\
\text { be consumed in sufficient quantity. }\end{array}$ & 67 & 18 & 15 \\
\hline 12 & Diabetics should not eat root vegetables. & 65 & 17 & 18 \\
\hline 13 & $\begin{array}{l}\text { Removing maad (broth) from rice while cooking helps reduce blood } \\
\text { sugar. }\end{array}$ & 54 & 20 & 26 \\
\hline 14 & COVID-19 vaccine causes harm to the diabetic patient & 27 & 58 & 15 \\
\hline 15 & Protein doesn't raise blood sugar, can be taken in large quantity & 29 & 43 & 28 \\
\hline
\end{tabular}

The result showed that age of the participants ( $\mathrm{rs}=0.10, \mathrm{p}=0.52)$, education level $(\mathrm{rs}=0.03$, $\mathrm{p}=0.82)$, and duration of illness $(\mathrm{rs}=0.15, \mathrm{p}=0.32)$ had a positive association with total score. Similarly, the basal metabolic rate ( $\mathrm{rs}=-0.10, \mathrm{p}=0.45)$ had a negative association. However, none of the results were of statistical significance for the corresponding p-value.

\section{Discussion:}

The mean age of our study population was 49.7 years, as age is one of the risk factors for the development of diabetes ${ }^{5}$. Similar findings are seen in previous studies where there is a high prevalence of diabetes among the elders ${ }^{6,7}$. Many patients are illiterate in our study group, as the educational level is positively associated with knowledge of the disease $e^{8}$. If the duration of diabetes is more, then awareness of DM would also be more due to positive association'. The majority of the diabetics in our study are not aware of the normal blood values and their significance and they do not know the type of diabetes they are suffering from, it might be because many of them were illiterate. So, proper education campaigns should be performed in simpler languages in which they can understand. More than half of the patients answered obesity as a risk factor for diabetes and it was also mentioned 
in other studies ${ }^{10,11}$. Many patients were taking two to three large meals compared to frequent small meals. A study done by Kahleova et a ${ }^{12}$ suggests that eating two large meals a day is more beneficial than six smaller meals in type 2 diabetes. Further studies are needed before recommending the meal frequency, especially in the Nepalese population.

Around $10 \%$ of patients answered of taking a double dose if they forget the previous dose, and this idea of them should be discouraged to prevent the hypoglycemic condition. In the present study, many patients felt that diabetes is caused by high sugar intake but only a few patients were aware of the lack of insulin or failure of the body to use insulin could lead to diabetes. This finding agrees with that of a study conducted by Foma et $\mathrm{a}^{13}$. Only about $1 / 3$ rd of them knew that diabetes could be familial. It implies that most patients are unaware that diabetes runs in family. These patients should be provided with appropriate education regarding the causes of diabetes. Knowledge of complications such as loss of vision and poor wound healing was more compared to heart failure and kidney failure. This finding is similar to the study done by Foma et $\mathrm{al}^{13}$.

In a study done by Alsous $\mathrm{M}$ et $\mathrm{al}^{14}, 16 \%$ of the participants reported that the use of complementary and alternative medicine (CAM) for better glycemic control, which is much lower than in our study. However, there are inter-country as well as intracountry variations that limit a direct comparison.

As a result of associated complications, diabetes intensifies the economic burdens both on health departments and patients themselves in developing countries like Nepal. According to Alanazi et $\mathrm{al}^{15}$, $48.7 \%$ of the respondents thought that lack of exercise and obesity were the major risk factors of DM, 33.2\% thought that it was a genetic disease when only $3.7 \%$ thought that it was through hypertension.

A sedentary lifestyle and bad eating habits have been blamed for the increasing prevalence of diabetes in developing countries like Nepal. The self-care practices of individuals are influenced by their knowledge about diabetes; the more they know about their illness, the more they would have self-management skills.

Many research works published have shown that the diabetic population doesn't have enough awareness of diabetes, the proper use of medications, lifestyle modifications, dietary plans, myths associated with insulin, and other educational programs on the health issue. As such DM is a key health problem globally. As it is a common metabolic disorder or problem with high prevalence so are myths and misconceptions. Thus, the myths and misconceptions can lead to poor glycemic control among diabetic people and may result in complications and then increase the incidence of morbidity and mortality. The study has shown low awareness of the population about various aspects of diabetes and motivating their diabetic family members to get their blood sugar test, blood pressure, urine test, and eye examination done as recommended by international guidelines. So, the authorities must take up mass education programs which would go a long way in the prevention and management of diabetes, especially in underdeveloped countries.

Awareness and knowledge about diabetes among diabetic patients were less in our study populations. All doctors, nurses, dietitians should help diabetic patients by providing the right information in a simpler language that they could understand and make them healthy. This can be done by issuing pamphlets of information about DM to diabetic patients with pictures showing the complication of diabetes and hypoglycemia, through public speaking sessions to address the general public.

The study highlighted the need of people in Nepal for better health information through large-scale awareness interventions regarding diabetes. In addition, diabetic patients' adherence to their antidiabetic therapy can be achieved through patient counseling by a clinical pharmacist or health professional to improve diabetes care and can go 
a long way in the prevention and management of diabetes in Nepal. There is a big space for raising educational awareness about diabetes through formal, well-organized approaches by healthcare professionals in hospitals, clinics, and communitybased healthcare centers. It is highly recommended that healthcare professionals both collaboratively and individually develop programs and projects.

There are some limitations to this study. The investigators noted that some of the responses to the questions on the diabetes myth section were due to guessing despite the availability of the 'do not know' option. The participants enrolled were from the outpatient department so their responses might not reflect the sicker admitted patients with diabetes mellitus. Furthermore, not all questions regarding the myths of diabetes were included in the study.

\section{Conclusion:}

The patients with diabetes exhibited poor knowledge and awareness regarding the disease and had significant myths and misconceptions about their illness. The level of knowledge regarding diabetes mellitus did not correlate with the age of the participant, duration of illness, education level, or body mass index.

\section{List of abbreviations}

COVID-19: Coronavirus Disease 2019, DM: Diabetes Mellitus, BMI: Body Mass Index, OHA: Oral Hypoglycemic Agent, CAM: Complementary and Alternative Medicine

\section{Competing interests}

The authors declare that they have no competing interests.

\section{Authors' contributions}

SS conceptualized, collected data, analyzed and wrote the manuscript. PR and FA were involved in data collection and analysis of the data. All authors read and approved the final manuscript.

\section{Acknowledgements}

We thank to all the respondents without whom we would not have been able to share this effort.

\section{References:}

1. Wändell PE, Brorsson B, Åberg H, Quality of life in diabetic patients registered with primary health care services in Sweden, Scandinavian journal of primary health care. 15:2 (1997) 97102. DOI: $10.3109 / 02813439709018495$.

2. Alberti KG, Zimmet P, Shaw J, International Diabetes Federation: a consensus on Type 2 diabetes prevention, Diabetic Medicine. 25:4 (2007) 451-63. DOI: 10.1111/j.14645491.2007.02157.x.

3. Guariguata L, Whiting DR, Hambleton I, Beagley J, Linnenkamp U, Shaw JE, Global estimates of diabetes prevalence for 2013 and projections for 2035, Diabetes Res Clin Pract. 103:2 (2014) 137-49. DOI: 10.1016/j. diabres.2013.11.002.

4. Shrestha N, Mishra SR, Ghimire S, Gyawali B, Mehata S, Burden of Diabetes and Prediabetes in Nepal: A Systematic Review and MetaAnalysis, Diabetes Ther. 11:9 (2020) 19351946. DOI: $10.1007 / \mathrm{s} 13300-020-00884-0$.

5. King $H$, Rewers $M$, Global estimates for prevalence of diabetes mellitus and impaired glucose tolerance in adults, WHO Ad Hoc Diabetes Reporting Group, Diabetes Care. 16:1 (1993) 157-177. DOI: 10.2337/ diacare.16.1.157.

6. American Diabetes Association, Diagnosis and classification of diabetes mellitus, Diabetes care. 32:1 (2009) S62-7. DOI: 10.2337/ dc10-S062.

7. Gannon MC, Nuttall FQ, Westphal SA, Fang $\mathrm{S}$, Ercan-Fang N, Acute metabolic response to high-carbohydrate, high-starch meals compared with moderate-carbohydrate, lowstarch meals in subjects with type 2 diabetes, Diabetes Care. 21:10 (1998) 1619-26. DOI: 10.2337/diacare.21.10.1619.

8. Silva-Tinoco R, Cuatecontzi-Xochitiotzi T, la Torre-Saldaña D, León-García E, SernaAlvarado J, Orea-Tejeda A, et al, Influence 
of social determinants, diabetes knowledge, health behaviors, and glycemic control in type 2 diabetes: an analysis from real-world evidence, BMC endocrine disorders. 20:1 (2020) 1-11. DOI: 10.1186/s12902-020-00604-6.

9. Deepa M, Bhansali A, Anjana RM, Pradeepa R, Joshi SR, Joshi PP, et al, Knowledge and awareness of diabetes in urban and rural India: the Indian Council of Medical Research India diabetes study (phase I): Indian Council of Medical Research India diabetes 4, Indian journal of endocrinology and metabolism. 18:3 (2014) 379-85. DOI: $10.4103 / 2230$ 8210.131191 .

10. Alanazi FK, Alotaibi JS, Paliadelis P, Alqarawi $\mathrm{N}$, Alsharari A, Albagawi B, Knowledge and awareness of diabetes mellitus and its risk factors in Saudi Arabia, Saudi medical journal. 39:10 (2018) 981-989. DOI: 10.15537/ smj.2018.10.22938.

11. Yumuk V, Frühbeck G, Oppert JM, Woodward E, Toplak H, An EASO position statement on multidisciplinary obesity management in adults, Obesity facts. 7:2 (2014) 96-101. DOI: 10.1159/000362191.
12. Kahleova $\mathrm{H}$, Belinova L, Malinska $\mathrm{H}$, Oliyarnyk O, Trnovska J, Skop V, et al, Eating two larger meals a day (breakfast and lunch) is more effective than six smaller meals in a reduced-energy regimen for patients with type 2 diabetes: a randomised crossover study, Diabetologia. 57:8 (2014) 1552-60. DOI: 10.1007/s00125-014-3253-5.

13. Foma MA. Saidu Y1, Omoleke SA, Jafali J, Awareness of diabetes mellitus among diabetic patients in the Gambia: a strong case for health education and promotion, BMC Public Health. 5:13 (2013) 1124. DOI: 10.1186/1471-245813-1124.

14. Alsous M, Abdel Jalil M, Odeh M, Al Kurdi R, Alnan M, Public knowledge, attitudes and practices toward diabetes mellitus: a crosssectional study from Jordan, PloS one. 14:3 (2019) e0214479. DOI: 10.1371/journal. pone. 0214479 .

15. Alanazi FK, Alotaibi JS, Paliadelis P, Alqarawi $\mathrm{N}$, Alsharari A, Albagawi B, Knowledge and awareness of diabetes mellitus and its risk factors in Saudi Arabia, Saudi medical journal. 39:10 (2018) 981-989. DOI: 10.15537/ smj.2018.10.22938. 